\title{
Article
}

\section{Back to the Future - In support of a renewed emphasis on generic agility training within sports-specific developmental pathways}

Liefeith, Andreas Karl, Kiely, J., Collins, D., and Richards, J.

Available at http://clok.uclan.ac.uk/21843/

Liefeith, Andreas Karl, Kiely, J. ORCID: 0000-0001-9817-0224, Collins, D., ORCID: 0000-0002-7601-0454 and Richards, J. ORCID: 0000-0002-4004-3115 (2018) Back to the Future - In support of a renewed emphasis on generic agility training within sports-specific developmental pathways. Journal of Sports Sciences, 36 (19). pp. 2250-2255. ISSN 0264-0414

It is advisable to refer to the publisher's version if you intend to cite from the work. http://dx.doi.org/10.1080/02640414.2018.1449088

For more information about UCLan's research in this area go to http://www.uclan.ac.uk/researchgroups/ and search for <name of research Group>.

For information about Research generally at UCLan please go to http://www.uclan.ac.uk/research/

All outputs in CLoK are protected by Intellectual Property Rights law, including Copyright law. Copyright, IPR and Moral Rights for the works on this site are retained by the individual authors and/or other copyright owners. Terms and conditions for use of this material are defined in the policies page. 
Back to the Future - in support of a renewed emphasis on generic agility training within sports-specific developmental pathways

ANDREAS LIEFEITH ${ }^{1}$, JOHN KIELY ${ }^{2}$, DAVE COLLINS ${ }^{2}$ and JIM RICHARDS $^{3}$

${ }^{1}$ Faculty of Health and Life Science, York St John University, York, UK; ${ }^{2}$ Institute of Coaching and Performance, University of Central Lancashire, UK and ${ }^{3}$ Department of Allied Health Professions Unit, School of Health Sciences, University of Central Lancashire, UK

Correspondence: Andreas Liefeith, York St John University, Lord Mayor's Walk, York, UK. E-mail: a.liefeith@yorksj.ac.uk 


\title{
Back to the Future - in support of an increased emphasis on generic agility training within sports-specific developmental pathways
}

\begin{abstract}
Perhaps as a consequence of increased specialism in training and support, the focus on engendering and maintaining agility as a generic quality has diminished within many contemporary sports performance programmes. Reflecting this, we outline a rationale suggesting that such a decreased focus represents an oversight which may be detrimental to maximising the potential of performers. We present an evidence-based argument that both generic and specific elements of agility performance should be consistently emphasised within long-term performance-training programmes. We contend that prematurely early specialisation in athlete development models can diminish focus on generic movement skill development with a subsequent detriment in adult performance. Especially when this is coupled with poor primary physical education and limited movement experiences. More speculatively, we propose that generic agility can play a role in operationalising movement development through facilitating skill transfer: thereby enabling the learning of new skills, reduce incidence of injury and facilitating re-learning of old skills during rehabilitation and Return-to-Play processes.
\end{abstract}

Keywords: generic agility, specific skills, transfer, injury.

Although the importance of agility has been acknowledged as a key contributor to sporting success (e.g. Chelladurai, 1976), particularly in team sports (Paul, Gabbett, \& Nassis, 2016), the extent and nature of this contribution remains clouded. Currently, the agility phenomenon lacks a clear and universally accepted definition (Young, Dawson, \& Henry, 2015) and there seems to be an insufficiency of sensitive quantification tools (Nimphius, Callaghan, Bezodis \& Lockie, 2017). The absence of 
a coherent conceptual framework contributes to a sense that, although all agree that agility is important, we are not quite certain what exactly it is. Nor are we clear on how it may be measured, how it may be optimally developed and most crucially, how it may ultimately contribute to long-term performance objectives.

The focus on engendering, maintaining and enhancing agility has seemingly diminished within many contemporary sports performance programmes. This may be due to a range of conspiring factors, such as modern systemic pressures, poorly construed performance models and ever younger sports-specific specialisation (Sugimoto, Stracciolini, Dawkins, Meehan, \& Micheli, 2017). This has led to practices in talent development that have marginalised the role of generic agility. The manifestation of which may be seen in the impact of early specialisation on reducing the exposure of young athletes to a variety of sporting activities (cf. Mostafavifar, Best, \& Myer, 2013). In this paper, in contrast to contemporary tends, we outline a rationale proposing that this decreased focus on generic agility represents an oversight, which may ultimately compromise the performance potential of athletes. Given the ubiquitous, yet variously employed uses of the term, we begin by clarifying our interpretation of the agility construct; outline the critical components underpinning agile athletic performance and finally propose how long-term generic agility training may provide players with performance and injury resilience benefits.

\section{What is Agility?}

Various definitions are offered within the literature, ranging from the broad (e.g. "the efficiency of movement throughout the entire kinetic chain regardless of the skill being executed", Giles, Penfold \& Giorgi, 2005 cited in Giles, 2007, p. 9), to the more specific, (e.g. the ability to maintain or control body position while quickly changing 
direction during a series of movements, Twist \& Benickly, 1996). Other definitions are even more explicit in focusing uniquely on the perceptual and cognitive components of agility, acknowledging that changes in direction are commonly undertaken in response to external stimuli (e.g. Benvenuti, Minganti, Condello, Capranica, \& Tessitore, 2010; Young \& Willey, 2010). Indeed, Paul, Gabbett \& Nassis (2016) use the word agility to exclusively describe a perceptual decisionmaking process in response to a stimulus. Such authors also highlight that these factors are often declared as defining factors in agility performance though the underlying mechanisms involved are less well understood.

While such definitions are seductive in their clarity, things are often more complex than suggested. Movements may be forceful, may variously require movement through an extended range of motion, and involve complex limb-to-limb or eye-to-limb coordination, and yet not necessarily fit with the common definitions of agile behaviour presented above. For example, an important characteristic of the practical coaching perception of agility, which has thus far eluded articulation within single-sentence definitions, is that agile behaviours are generally perceived as being executed at the very edge of motor capabilities. Consequently, we suggest that agility should be conceived as describing movement solutions which require the dynamic integration of a number of sub-capacities (speed, forceful contraction, mobility, dexterity, balance, postural control, coordination, perceptual awareness, reflexive decision making, etc.) in some complex and challenging permutation to satisfy the demands imposed by a rapidly changing physical context. It may therefore be posited that a wide range of contributing sub-capacities enable agile behaviour. Furthermore, when executing any agility task, some of these sub-capacities should be extensively challenged. As one of many potential practical implications therefore, difficult 
movement challenges (such as work to extend your skill range or recovering from injury) are essentially and unavoidably facilitated by high levels of agility.

The nature of encountered movement problems and thus, the agility demands placed upon a performer, vary extensively depending upon sporting context. The agility of the cross-country runner, the triple jumper, the rock-climber and the tabletennis player are all, in executional terms, very different. Yet, at a generalised level, it also seems apparent that agile behaviour is ultimately enabled by a common set of underpinning capacities. Consider, for example, Giblin, Collins, MacNamara and Kiely (2014) and MacNamara, Collins and Giblin (2015) on the essential nature of basic (generic) agility for subsequent development of (specific) skill. Giblin et al. (2014) identify that adequate movement skills underpin several factors impacting physical activity, ranging from habitual daily tasks to elite-level sports performance. Importantly, such generic skills underpin the athlete's ability to meet any variability of challenge. This is obvious in games players, where the level of variability in the demands of play is extensive. Even closed sport skills hold significant variability in their challenges, for example, varied wind, run ups or take off dynamics in the triple jump. Furthermore, variation is required of the athlete through changes associated with many factors, such as growth, training, ageing and injury. In short, athletes have an inherent need to handle variable challenge and we suggest, generic agility provides the equipment necessary to meet this challenge.

Thus, agility may be considered an abstract, over-arching and super-ordinate capacity, enabled by the coordinated blending of numerous contributing subcapacities. We refer to abstract in the sense that it is these sub-capacities, physical entities or biological processes, that combine to create a specific movement output, whilst agility is the conceptual framework which encompasses these components. 
Therefore, the development of agility should surely be an essential feature at every stage of an athletes' development. To fulfil these various roles, the agility construct may be conceptualised as having both generic and specific components. The generic characterised by an ability to efficiently negotiate a diversity of movement challenges, underpinned by a range of well-developed sub-capacities. The specific characterised by an ability to more quickly and/or accurately solve the narrower sub-set of movement problems commonly posed within a particular sporting context. Building on the ideas expressed above, we present an argument that both generic and specific elements of agility performance should be consistently emphasised within long-term performance training programmes. But before this, we present the case that current, in vogue Athlete Development (AD) models may have acted to curtail the generic agility base essential to subsequent development.

\section{Why has generic agility training diminished?}

The root of this problem may, at least in part, lay with the AD processes currently in common usage. Over the course of recent decades many sporting cultures have embraced early-specialisation models (Smith, 2015; Torres, 2015). The trend within $\mathrm{AD}$ being to recruit future performers at progressively younger ages, thereby extending exposure to learning experiences focused upon optimising future sportspecific performance (Myer et al., 2016). Although issues related to such AD models have been acknowledged previously (e.g. Bailey \& Collins, 2013; Ford et al., 2011), we feel it is pertinent to highlight the historical and contemporary impact of these models on the development and maintenance of generic agility.

Early focus and subsequently increased volume of context-specific learning experiences, has surely contributed to ever-increasing levels of task-specific 
performance in many domains. However, there remains lingering doubt as to the universal applicability of early-specialisation dogma. In our eagerness to imprint sports-specific capacities on ever-younger performers, perhaps to fulfil misguided short-term agendas (Collins et al., 2011), are the potential benefits bestowed by certain generic capacities being overlooked, undermined and under-developed? Is an early focus on sports-specific agility, at the expense of a concomitantly reduced focus on generic agility, a developmental strategy which ultimately promotes, or inhibits, optimised long-term sporting performance?

A related point is the pervading idea that sports-specific performance is always best served by extensive, sports-specific practice (cf. Ericsson, Krampe, \& TeschRömer, 1993). For example, a defining characteristic of some published AD models (e.g. Long Term Athlete Development - Bayli \& Hamiliton, 2004) is the segregation of the overall developmental process into progressive blocks, whereby attributes and capacities developed in preceding stages are utilised, and capitalised upon, in subsequent periods. The underpinning rationale being that specific stages of chronological maturity are accompanied by specific windows of opportunity, i.e. critical periods which provide a unique opportunity to embed specific athletic characteristics. It is suggested that if appropriate training stimuli are not imposed within the timeframe presented by such windows, then the opportunity for targeted development, is either completely lost, or severely diminished (Bayli \& Hamiliton, 2004). This implication is seemingly not supported by previous literature. Bailey et al. (2010) highlight that, although there maybe plausible benefits in identifying periods of time where greater improvements may occur, there remains a lack of populationspecific evidence to support this. Baker, Côté, and Abernethy (2003) also identified that expert decision-makers in team sports specialised relatively late, having first 
experienced a very broad base of sporting experiences in their earlier years. Similarly, the Bayli position has been previously questioned from a physiological perspective (Ford et al., 2011) with regards to specific windows of physical development.

Accordingly, broad experience seems to be functionally beneficial, both developmentally and for longer term attainment. Indeed, Bailey \& Collins (2013) highlight research (cf. Polman, Walsh, Bloomfield, \& Nesti et al., 2004) suggesting that, while it might be productive to develop fundamental movement skills during early childhood, it is not exclusive to this time frame as these skills can be continually developed into adulthood. Unfortunately (in our view), numerous sport governing bodies have prematurely applied $\mathrm{AD}$ systems, or the equally challenged pyramid approach (Bailey \& Collins, 2013), with each sport vying for talented youngsters to enter pathways before the proposed 'critical periods' terminate.

The structural framework offered by AD models thus provides an apparently user-friendly and attractively simple long-term planning template for governing bodies, sporting institutions, and the coaches of young athletes. Although the primary assumption of $\mathrm{AD}$ philosophy may be eminently sensible, i.e. elite development requires extensive dedication of time and focused effort, there is an evident raft of associated secondary assumptions, offered as substantiation for particular AD guidelines, which appear less rationally justifiable.

Potentially and notably contradictory to other elements of this approach, established $\mathrm{AD}$ doctrine has also emphasised the importance of the early creation of fundamental movement skills, collectively defined as locomotive, manipulative and stabilisation skills (Lubans, Morgan, Cliff, Barnett, \& Okely, 2010), on which the subsequent development of higher level skills are supported (Balyi \& Hamiliton, 2004). Accordingly, the importance of early exposure to a broad range of movement 
skills, and the associated development of a broad spectrum of fundamental movement patterns, is frequently cited as a necessary condition for the advancement of higher order patterns (Berry, Abernethy, \& Côté, 2008; MacNamara et al., 2015). However, although AD models provide, at least superficially, a rational template upon which to base long-term athlete development strategies, three questions remain as to how these proposed developmental philosophies impact upon athletic agility. Firstly, while the importance of a broad movement base has been emphasised within early developmental training phases, many models seem to ignore the need for such an explicit emphasis (cf. Giblin et al., 2014), or assume that this physical literacy base can be accomplished through unstructured play (MacNamara et al., 2015). "Physical literacy can be described as the motivation, confidence, physical competence, knowledge and understanding to value and take responsibility for engagement in physical activities for life." (Whitehead, 2006, p. 127). In this paper we use the term focused on the elements of physical competence, although the other aspects are clearly important and interrelated. Importantly, although never really examined as a specific issue, many authors seem to accept the importance of physical literacy, or even gloss over it, whilst not considering the ways in which it should be addressed and developed (cf. Giblin, Collins, MacNamara et al., 2014; Giblin, Collins \& Burton 2014; MacNamara et al., 2015). As a result, the essential base is often neglected or underdeveloped (Burns, Fu, Fang, Hannon, \& Brusseau, 2017). Secondly, even when such provision is apparent in the early stages, this generalised movement exposure is often substantially withdrawn in subsequent developmental phases in favour of a heavy prioritisation to sports-specific skills (cf. Jess, Collins, \& Burwitz, 2002). The related concern being that consistent exposure to generic movement challenges may offer substantial long-term benefits to athletic performance potential (as we suggest 
later), which are not necessarily provided though sports-specific movements. Thirdly, much of the philosophy underpinning particular AD models is predicated upon the existence of 'critical periods' and 'windows of opportunity' for the installation of certain athletic phenotypes. This further exacerbates the trend towards early specialisation, as sports rush to ensure that the supposed benefits of these periods are fully realised. Yet empirical evidence supporting such assumptions is fundamentally lacking (cf. Ford et al., 2011). Of course, while absence of evidence is certainly not evidence of absence, if such theories are to claim any form of scientific validity, then the burden of proof surely lies with the proposers of long-term AD theories.

In contrast, a strong evidence-led argument highlights the detrimental consequences of early sports specialisation. As an illustration, recent reviews concluded that there is no evidence that intense training and specialisation before puberty is necessary to achieve elite status, whereas early sports specialisation increases incidence of injury, psychological stress and the likelihood of early deselection from sport (Jayanthi, Pinkham, Dugas, Patrick, \& LaBella, 2013; Myer et al., 2015). Consequently, it has been suggested that broad exposure to a wide diversity of movement and physiological challenges is necessary to promote physical resilience, and facilitate optimal movement skill development (e.g. Mostafavifar et al., 2013). For example, the National Athletic Trainers' Association recommends that young athletes delay specialisation and participate in multiple sports and recreational activities throughout the year to enhance general fitness and aid motor development (Valovich McLeod et al., 2011). Similarly, a consensus statement of the American Medical Society for Sports Medicine, focused on overuse injuries and psychoemotional burnout in youth sports, suggesting that a variety of physical and mental health concerns are directly attributable to early sports specialisation (DiFiori et al., 
2014). More positively, several sports are increasingly recognising the inherent disadvantages of this approach, especially when considered against the associated risks of early burnout and dropout, and sport-specific overuse injuries (e.g. Bronner, Ojofeitimi, \& Rose, 2003; Calhoon \& Fry, 1999; Dubravcic-Simunjak, Pecina, Kuipers, Moran \& Haspl, 2003; Jayanthi, LaBella, Fischer, Pasulka, \& Dugas 2015; Myer et al., 2016; Waldén, Hägglund, \& Ekstrand, 2007). The English Rugby Football League is one governing body that has deliberately raised the age of recruitment onto their scholarship system to avoid early specialisation and its associated problems (see also work in Centimetres, Grams or Seconds sports, Moesch, Elbe, Hauge, \& Wikman, 2011).

To summarise, current trends in many sports are typified by an ever-earlier recruitment of young talent, in turn leading to early diversion down sports-specific specialisation pathways and, consequently, less resource dedication to generic movement skill development. Consequently, perhaps, specific skill execution in that sport can reach ever higher standards with younger athletes. But, when challenges arise which require skills of a wider, more generic nature (we suggest an inevitable feature of sport), performers may lack the breadth of physical literacy needed to overcome them. We consider some of these challenges later. But first, are these benefits something which is solely a developmental concern with young athletes?

Factors underpinning agility performance - The need for generic and specific experience

While a strong argument exists for early generic training, are there equal benefits if this trend is extended into adulthood? We suggest that there are. Effective agility training should promote the dynamic emergence of safe and efficient movement 
solutions to address unique movement problems. The uniqueness, in origin, of each individual movement problem that may emerge are because of an ever-varying constellation of underlying factors, both intrinsic (speed, stability, fatigue, body orientation, motivational, etc.) and extrinsic (conditions underfoot, environmental factors, etc.). For example, the subtle magnitude and direction of force application variation required to accommodate wind speed in javelin throwing; or the use of wellestablished reflexive feedback pathways to accommodate asymmetrical loading in a judo throw.

Accordingly, regular exposure to a wide diversity of movement challenges can facilitate a thorough exploration of motor-perceptual space. A direct neuro-biological consequence of such expansive movement exploration is that cortical representations of the working musculature become ever-more refined and detailed. This, in turn, facilitates more precise neural regulation of muscle activation and thus movement control. Diversity of movement challenge may serve to drive a more precise cortical mapping of the working musculature, leading to an enhanced clarity of neural signal (for a review see, Neilson, \& Neilson, 2005). The practical benefits of enhanced mapping are increased precision in timing, and regulation of movement forces. Hence, regular exposure to agility-type diversity of movement challenge may logically facilitate athletes' movement efficiency, their repertoire of potential movement solutions, and their resilience to multiple dimensions of movement stress (Engineer et al., 2012).

The operations of this influence are increasingly acknowledged. Physical activity drives structural plasticity within the motor regions of the brain (e.g. Edgerton \& Roy, 2009; Thompson \& Wolpaw, 2014). In turn, structural plasticity supports everimproving communications between neuronal networks whose orchestrated activation 
facilitates skill development (Kiely, 2017). Such plasticity processes are not confined to the brain, however. Activity-dependent plasticity (Andriyanova, \& Lanskaia, 2014), driven by the characteristics of descending and peripheral inputs, also shapes neurological micro-architectures, throughout the neural system (e.g. Carson, 2006; Kiely, 2017). Although spinal adaptations have been less thoroughly investigated than their counterparts in the cortex, the emerging consensus is that they are critical to supporting changes in movement control and coordination (Pelletier, Higgins, \& Bourbonnais, 2015). Thus, structural modifications of many forms, from the strengthening of synaptic connections to the thickening of the myelin sheath surrounding neuronal axons, may be unseen, but ultimately underpin all physical training related performance improvements. It is these pervasive changes, evident at multiple levels throughout the athlete's neurobiological system, which enable the gradual embedding of movement habits and proficiencies. Recently emerged evidence illustrating that such adaptive neuro-plasticity is possible throughout the lifespan (e.g. Kleim \& Jones, 2008; Merzenich, Van Vleet, \& Nahum, 2014) may be particularly relevant to senior athletes who question the potential benefits accruing from generic agility training. Recent evidence suggests that optimally facilitating neuro-plastic processes in mature nervous systems demands that certain fundamental criteria are fulfilled. Specifically, that the movements performed are novel, nonformulaic, relevant and challenging to the athlete (e.g. Avanzino et al., 2014; Engineer et al., 2012); these criteria seemingly overlap with the fundamental descriptors of generic agility movement challenges.

\section{The role of agility in injury rehabilitation}


Neuroscience may again offer a mechanism that helps us understand how generic agility may positively contribute to post-injury rehabilitation processes (Elbert \& Rockstroh, 2004). Injury (by common definition) typically results in the loss of training opportunity for some period. The nature of plasticity within the motor cortex entails that periods of muscular disuse result in a gradual degradation of cortical representations of the inactive muscle (Coq \& Barbe, 2011; Pelletier et al., 2015). Accordingly, sustained periods of disuse are manifest not solely in negative muscular consequences, but also in an increasingly blurred representation of the effected muscular regions within the cortex (Pelletier et al., 2015). Such signalling degradation inevitably leads to a host of negative movement performance outcomes (Pelletier et al., 2015). A fundamental priority of an effective rehabilitation process is the reconfiguration of the correspondence between cortical motor maps and the injuryeffected musculature (Thompson \& Wolpaw, 2014; Wolpaw \& Tennissen, 2001). Once more, the process which drives such cortical re-configuration is repeated exposure to novel and varied movement challenges. We therefore suggest that early, and regular, exposure to an appropriately tailored diversity of agility-type movement challenges should be considered a cornerstone of any comprehensive injury rehabilitation protocol.

\section{Facing challenges across the athlete lifespan}

\section{The role of generic agility in meeting motoric challenges}

As stated earlier, generic movement ability appears to offer the best underpinning preparation for subsequent specific skills (Bailey \& Collins, 2013; Berry et al., 2008). There are, however, further benefits to building this firm base. What if, for example, the developing athlete encounters broader movement challenges (i.e. close to or even 
broader than the specific skill set s/he has built in their own sport)? Variability in skilled performance has being previously identified in elite performers. The variable way a successful performance outcome is achieved can improve the strategies used to cope with internal or external change; that is where adaptability to unexpected perturbations is required (Hiley, Zuevsky, \& Yeadon, 2013; Wilson, Simpson, Van Emmerik, \& Hamill, 2008). But is such high variation likely to occur? We contend yes, and that generic ability will offer the physical literacy and skills base to cope in several different bur rather common ways. These acute or chronic perturbations may include body changes due to growth spurts, or morphological changes from training effects. Changes in the role or playing position of a performer may provoke uncertainty as might the introduction of a new method or approach to technique development. This may also be influenced by skill refinement as opposed to mere skill acquisition (Carson \& Collins, 2015).

\section{The role of agility in movement performance \& injury resilience}

The proposed role of agility training in enriching both movement skill acquisition and on-going skill refinement may similarly find application in the nurturing of injury resilience. Generic agility development, whereby a: diversity of muscular-generated and momentum-imposed forces, coordinative patterns, dynamic stabilisation challenges, are experienced at a range of biomechanical positions will engender injury resilience through two mutually intertwined mechanisms. Firstly, through the enhancement of neural, spinal, and neuro-muscular signalling pathways (Pelletier et al., 2015; Thompson \& Wolpaw, 2014); and secondly, through the wide-ranging loading and conditioning of a fuller spectrum of muscular and biological tissues. This may avoid overuse injuries, by making movements 'broader' for example. 
It is important to recognise that these benefits will accrue from an optimum blend of specific and generic agility work; in other words, from movement challenges which are, by turns, closer to (specific) and more diverse than (generic) the target sport.

\section{Conclusion}

Based upon the various strands of evidence and ideas presented, we suggest that there is merit in debating that generic agility training may serve multiple potential purposes within high-performance pathways. Regular and persistent exposure to novel movement challenges variously prioritising differing facets of the generic agility construct, offers a more expansive range of performance benefits than is currently appreciated within early specialisation planning philosophies. In closing, an evidenceled rationale suggests that generic agility training can instil performance benefits which are not provided by exclusively sports-specific training protocols and overlystringent early specialisation AD models.

The benefits of generic agility training may be briefly summarised as:

(1) Through remediation of chronically overly-habituated dysfunctional movement characteristics, generic agility training may foster injury resilience and reduce the likelihood of overuse injuries

(2) On-going diversity of movement challenge creates an optimally fertile neurobiological environment for continuing re-calibration and refinement of existing sports-specific movement skills

(3) Finally, regular generic agility training facilitates an enhanced dynamic adaptability to cope with movement novelty, hence promoting optimised 
conditions for both the learning of new skills and the evolution of novel solutions to encountered movement problems

We hope that this paper offers a stimulus for debate and a reconsideration of the role for generic agility.

The authors report no conflicts of interest 


\section{References}

Andriyanova, E. Y., \& Lanskaia, O. V. (2014). Functional plasticity of spinal circuits in long-term sports activity adaptation. Human Physiology, 40(3), 299-309. doi.org/10.1134/S0362119714030025

Avanzino, L., Pelosin, E., Abbruzzese, G., Bassolino, M., Pozzo, T., and Bove, M. (2014). Shaping motor cortex plasticity through proprioception. Cerebral Cortex 24, 2807-2814. doi: 10.1093/cercor/bht139

Bailey, R.P, Collins, D., Ford, P., MacNamara, Á., Toms, M., \& Pearce, G. (2010). Participant development in sport: An academic review. Leeds: Sports Coach UK

Bailey, R., \& Collins, D. (2013). The Standard Model of Talent Development and Its Discontents. Kinesiology Review, 2(4), 248-259. doi.org/10.1123/krj.2.4.248

Baker, J., Côté, J., \& Abernethy, B. (2003). Sport-specific practice and the development of expert decision-making in team ball sports. Journal of Applied Sport Psychology, 15, 12-25. doi:10.1080/10413200390180035

Balyi, I. \& Hamilton, A. (2003) Long-term athlete development update: trainability in childhood and adolescence, Faster, Higher Stronger, 20, 6-8

Balyi, I., \& Hamilton, A. (2004). Long-term athlete development: trainability in childhood and adolescence. Windows of opportunity. Optimal trainability. National Coaching Institute, Victoria, B.C., Canada \& Advanced Training and Performance Ltd. Victoria, B.C., Canada

Balyi, I., \& Hamilton, A. (2010). Long-term athlete development: trainability in childhood and adolescence. Windows of opportunity. Optimal trainability. American swimming, 2010, 14-23. 
Benvenuti, C., Minganti, C., Condello, G., Capranica, L., \& Tessitore, A. (2010). Agility assessment in female futsal and soccer players. Medicina (Kaunas, Lithuania), 46, 415-20. Retrieved from http://www.ncbi.nlm.nih.gov/pubmed/20944450

Berry, J., Abernethy, B., \& Côté, J. (2008). The contribution of structured activity and deliberate play to the development of expert perceptual and decision-making skill. Journal of Sport \& Exercise Psychology, 30, 685-708.

Bronner, S., Ojofeitimi, S., \& Rose, D. (2003). Injuries in a Modern Dance Company: Effect of Comprehensive Management on Injury Incidence and Time Loss. The American Journal of Sports Medicine, 31(3), 365-373. doi.org/10.1177/03635465030310030701

Burns, R. D., Fu, Y., Fang, Y., Hannon, J. C., \& Brusseau, T. A. (2017). Effect of a 12-Week Physical Activity Program on Gross Motor Skills in Children. Perceptual and Motor Skills, 124(6), 1121-1133. doi.org/10.1177/0031512517720566

Calhoon, G., \& Fry, A.C. (1999). Injury rates and profiles of elite competitive weightlifters. Journal of Athletic Training, 34, 232-238.

Carson, H. J., \& Collins, D. (2015). Tracking technical refinement in elite performers: The good, the better, and the ugly. International Journal of Golf Science, 4(1), 67-87. doi.org/dx.doi.org/10.1123/ijgs.2015-0003

Carson, R.G. (2006). Changes in muscle coordination with training. Journal of Applied Physiology, 101, 1506-1513. doi:10.1152/japplphysiol.00544.2006

Chelladurai, P. (1976). Manifestations of agility. Canadian Association Health Physical Education Recreation, 42, 36-41. 
Collins, D., Bailey, R., Ford, P.A., MacNamara, A., Toms, M. \& Pearce, G. (2011). Three worlds: new directions in participant development in sport and physical activity. Sport, Education and Society, 17, 225-243. doi:10.1080/13573322.2011.607951

Coq, J. O., and Barbe, M. F. (2011). Peripheral and central changes combined induce movement disorders on the basis of disuse or overuse In B. J. Larsen (Ed.), Movement Disorders: Causes, Diagnoses and Treatments, (pp. 1-41). Hauppauge, NY: Nova Science Publishers Inc.

Sugimoto, D., Stracciolini, A., Dawkins, C. I., Meehan, W. P., \& Micheli, L. J. (2017). Implications for Training in Youth. Strength and Conditioning Journal, 39(2), 77-81. doi.org/10.1519/SSC.0000000000000289

Department for Education. (2014) The national curriculum in England: Framework document. London, UK: Author

DiFiori, J. P., Benjamin, H. J., Brenner, J. S., Gregory, A., Jayanthi, N., Landry, G. L., \& Luke, A. (2014). Overuse injuries and burnout in youth sports: a position statement from the American Medical Society for Sports Medicine. British Journal of Sports Medicine, 48(4), 287-288. doi.org/10.1136/bjsports-2013-093299

Dubravcic-Simunjak, S., Pecina, M., Kuipers, H., Moran, J., \& Haspl, M. (2003). The Incidence of Injuries in Elite Junior Figure Skaters. The American Journal of Sports Medicine, 31(4), 511-517. doi.org/10.1177/03635465030310040601

Edgerton, V.R., \& Roy, R.R. (2009). Activity-dependent plasticity of spinal locomotion: implications for sensory processing. Exercise and Sport Sciences Reviews, 37, 171-178. 
Elbert, T., \& Rockstroh, B. (2004). Reorganization of Human Cerebral Cortex: The Range of Changes Following Use and Injury. The Neuroscientist, 10(2), 129-141. doi.org/10.1177/1073858403262111

Engineer, N. D., Engineer, C. T., Reed, A. C., Pandya, P. K., Jakkamsetti, V., Moucha, R., \& Kilgard, M. P. (2012). Inverted-U function relating cortical plasticity and task difficulty. Neuroscience, 205, 81-90. doi.org/10.1016/j.neuroscience.2011.12.056

Ericsson, K.A., Krampe, R.T. \& Tesch-Romer, C. (1993). The role of deliberate practice in the acquisition of expert performance. Psychological Review, 100, 363406.

Ford, P., Collins, D., Bailey, R.P., MacNamara, Á., Toms, M. \& Pearce, G. (2011). Participant Development in Sport, Exercise and Physical Activity: the Impact of Biological Maturation. European Journal of Sport Science, 1-21, ifirst

Giblin, S., Collins, D. \& Button, C. (2014). Physical literacy: importance, assessment and future directions. Sports Medicine. 44, 1177-1184, doi:10.1007/s40279-0140205-7.

Giblin, S., Collins, D. MacNamara, A. \& Kiely, J. (2014). The Third Way: Deliberate Preparation as an evidence-based focus for primary physical education. Quest, 66, 385-395, doi:10.1080/00336297.2014.944716

Giles, K. (2007). Develop physical competencies: the cornerstone of long term athlete development. Modern athlete and coach, 45(1), 8-12.

Hiley, M. J., Zuevsky, V. V., \& Yeadon, M. R. (2013). Is skilled technique characterized by high or low variability? An analysis of high bar giant circles. Human Movement Science, 32(1), 171-180. doi.org/10.1016/j.humov.2012.11.007 
Jayanthi, N., Pinkham, C., Dugas, L., Patrick, B., \& LaBella, C. (2013). Sports Specialization in Young Athletes. Sports Health: A Multidisciplinary Approach, 5(3), 251-257. doi.org/10.1177/1941738112464626

Jayanthi, N. A., LaBella, C. R., Fischer, D., Pasulka, J., \& Dugas, L. R. (2015). SportsSpecialized Intensive Training and the Risk of Injury in Young Athletes. The American Journal of Sports Medicine, 43(4), 794-801. doi.org/10.1177/0363546514567298

Jess, M., Collins, D., \& Burwitz, L. (2002). Children and physical activity: The centrality of basic movement skill development Proceedings of the ICHPER.SD Conference, London, England.

Kiely, J. (2017). The Robust Running Ape: Unraveling the Deep Underpinnings of Coordinated Human Running Proficiency. Frontiers in Psychology, 8(JUN), 1-10. doi.org/10.3389/fpsyg.2017.00892

Kirk, D. (2005). Physical Education, Youth sport and lifelong participation: the importance of early learning experiences. European Physical Education Review, 11, 239-255. doi:10.1177/1356336X05056649

Kleim, J.A., \& Jones, T.A. (2008). Principles of experience-dependent neural plasticity: implications for rehabilitation after brain damage. Journal of Speech, Language, and Hearing Research, 51(1), S225-S239. doi:10.1044/1092$4388(2008 / 018)$

Lubans, D. R., Morgan, P. J., Cliff, D. P., Barnett, L. M., \& Okely, A. D. (2010). Fundamental movement skills in children and adolescents. Review of associated health benefits. Sport Medicine, 40(12), 1019-1035. doi:10.2165/11536850000000000-00000 
MacNamara, Á., Collins, D. \& Giblin, S. (2015). Just let them play? Deliberate preparation as the most appropriate foundation for lifelong physical activity. Frontiers in Psychology, October, doi.org/10.3389/fpsyg.2015.01548

Merzenich, M. M., Van Vleet, T. M., \& Nahum, M. (2014). Brain plasticity-based therapeutics. Frontiers in Human Neuroscience, 8(June), 1-16. doi.org/10.3389/fnhum.2014.00385

Mostafavifar, A. M., Best, T. M., \& Myer, G. D. (2013). Early sport specialisation, does it lead to long-term problems? British Journal of Sports Medicine, 47(17), 10601061. doi.org/10.1136/bjsports-2012-092005

Moesch, K., Elbe, A. M., Hauge, M. L. T., \& Wikman, J. M. (2011). Late specialization: the key to success in centimeters, grams, or seconds (cgs) sports. Scandinavian Journal of Medicine and Science in Sports, 21(6) e282-e290. doi.org/10.1111/j.1600-0838.2010.01280.x

Myer, G. D., Jayanthi, N., Difiori, J. P., Faigenbaum, A. D., Kiefer, A. W., Logerstedt, D., \& Micheli, L. J. (2015). Sport Specialization, Part I: Does Early Sports Specialization Increase Negative Outcomes and Reduce the Opportunity for Success in Young Athletes? Sports Health: A Multidisciplinary Approach, 7(5), 437-442. doi.org/10.1177/1941738115598747

Myer, G. D., Jayanthi, N., DiFiori, J. P., Faigenbaum, A. D., Kiefer, A. W., Logerstedt, D., \& Micheli, L. J. (2016). Sports Specialization, Part II: Alternative Solutions to Early Sport Specialization in Youth Athletes. Sports Health: A Multidisciplinary Approach, 8(1), 65-73. doi.org/10.1177/1941738115614811

Neilson, P. D., \& Neilson, M. D. (2005). Motor maps and synergies. Human Movement Science, 24, 774-797. doi:10.1016/j.humov.2005.09.008 
Nimphius, S., Callaghan, S. J., Bezodis, N. E., \& Lockie, R. G. (2017). Change of Direction and Agility Tests: Challenging Our Current Measures of Performance. Strength and Conditioning Journal, 1-13. doi.org/10.1519/SSC.0000000000000309

Paul, D. J., Gabbett, T. J., \& Nassis, G. P. (2016). Agility in Team Sports: Testing, Training and Factors Affecting Performance. Sports Medicine, 46(3), 421-442. doi.org/10.1007/s40279-015-0428-2

Pelletier, R., Higgins, J., \& Bourbonnais, D. (2015). Is neuroplasticity in the central nervous system the missing link to our understanding of chronic musculoskeletal disorders? BMC Musculoskeletal Disorders, 16(1), 25. doi.org/10.1186/s12891-0150480-y

Polman, R., Walsh, D., Bloomfield, J., \& Nesti, M. (2004). Effective conditioning of female soccer players. Journal of Sports Sciences, 22, 191-203. doi:10.1080/02640410 310001641458

Smith, M. M. (2015). Early Sport Specialization: A Historical Perspective. Kinesiology Review, 4(3), 220-229. doi.org/10.1123/kr.2015-0024

Thompson, A. K., \& Wolpaw, J. R. (2014). The Simplest Motor Skill: Mechanisms and Applications of Reflex Operant Conditioning. Exercise and Sport Science Review, 42(2), 82-90. doi.org/10.1016/j.surg.2006.10.010.Use

Torres, C. R. (2015). Better Early Than Late? A Philosophical Exploration of Early Sport Specialization. Kinesiology Review, 4(3), 304-316. doi.org/10.1123/kr.20150020 
Twist, P.W., \& Benicky, D. (1996). Conditioning lateral movements for multi-sport athletes: Practical strength and quickness drills. Strength and Conditioning, 18(5), 1019.

Valovich McLeod, T. C., Decoster, L. C., Loud, K. J., Micheli, L. J., Parker, J. T., Sandrey, M. A., \& White, C. (2011). National Athletic Trainers' Association Position Statement: Prevention of Pediatric Overuse Injuries. Journal of Athletic Training, 46(2), 206-220. doi.org/10.4085/1062-6050-46.2.206

Waldén, M., Hägglund, M., \& Ekstrand, J. (2007). Football injuries during European Championships 2004-2005. Knee Surgery, Sports Traumatology, Arthroscopy, 15(9), 1155-1162. doi.org/10.1007/s00167-007-0290-3

Wilson, C., Simpson, S. E., Van Emmerik, R. E. A., \& Hamill, J. (2008). Coordination variability and skill development in expert triple jumpers. Sports Biomechanics, 7(1), 2-9. doi.org/10.1080/14763140701682983

Wolpaw, J. R., \& Tennissen, A. M. (2001). Activity-Dependent Spinal Cord Plasticity in Health and Disease. Annual Review of Neuroscience, 24(1), 807-843. doi.org/10.1146/annurev.neuro.24.1.807

Young, W. B., Dawson, B., \& Henry, G. J. (2015). Agility and Change-of-Direction Speed are Independent Skills: Implications for Training for Agility in Invasion Sports. International Journal of Sports Science \& Coaching, 10, 159-169. doi: 10.1260/1747-9541.10.1.159

Young, W. B., \& Willey, B. (2010). Analysis of a reactive agility field test. Journal of Science and Medicine in Sport, 13, 376-378. doi:10.1016/j.jsams.2009.05.006 